\title{
ELECTRONICS III
}

\author{
G. D. Bishop \\ Head of Engineering Department, \\ Moston College of Further Education, \\ Manchester
}




\section{Macmillan Technician Series}

P. Astley, Engineering Drawing and Design II

P. J. Avard and J. Cross, Workshop Processes and Materials I

G. D. Bishop, Electronics II

G. D. Bishop, Electronics III

J. Elliott, Building Science and Materials

J. Ellis and N. Riches, Safety and Laboratory Practice

D. E. Hewitt, Engineering Science II

P. R. Lancaster and D. Mitchell, Mechanical Science III

R. Lewis, Physical Science I

Noel M. Morris, Electrical Principles II

Noel M. Morris, Electrical Principles III
(C) G. D. Bishop 1979

All rights reserved. No part of this publication may be reproduced or transmitted, in any form or by any means, without permission.

First published 1979 by

THE MACMILLAN PRESS LTD

London and Basingstoke

Associated companies in Delhi Dublin

Hong Kong Johannesburg Lagos Melbourne

New York Singapore and Tokyo

\section{British Library Cataloguing in Publication Data}

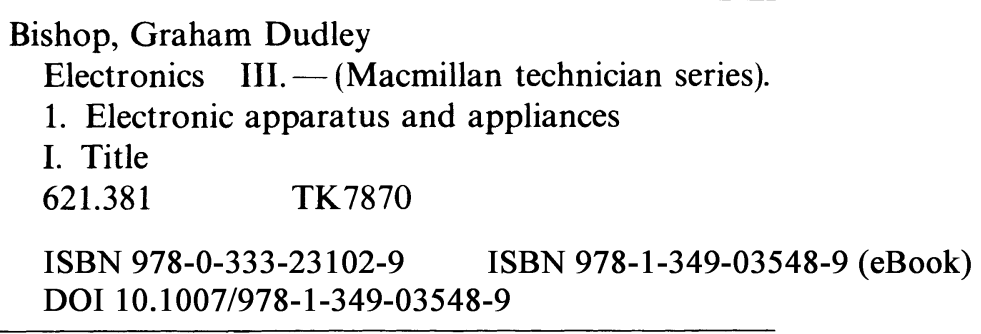

This book is sold subject to the standard conditions of the Net Book Agreement.

The paperback edition of this book is sold subject to the condition that it shall not, by way of trade or otherwise, be lent, resold, hired out, or otherwise circulated without the publisher's prior consent in any form of binding or cover other than that in which it is published and without a similar condition including this condition being imposed on the subsequent purchaser. 


\section{Contents}

Foreword

Preface

\section{Field-effect Transistors}

1.1 FET Operation and Characteristics

1.2 FET Circuits

\section{Amplifiers}

2.1 Class A, B, AB and C Operation

2.2 Two-stage Class A Common-emitter Amplifier

2.3 Measurement of Amplifier Performance

2.4 Radio Frequency Amplifiers

2.5 Audio Frequency Large-signal Amplifiers

2.6 Measurement of Large-signal Amplifier Performance

2.7 Parasitic Oscillation

2.8 Buffer Amplifiers and Impedance-matching

\section{Noise}

3.1 Noise Characteristics

3.2 Noise in Amplifiers and Receivers
1

\section{Section A}

Describes basic construction of FETs; explains differences between depletion and enhancement modes; compares properties with valves and bipolar transistors; states precautions taken when using FETs; determines characteristics

Describes circuit applications of FETs; calculates stage gain; describes effect of inductive load; describes performance with tuned circuit load; states use of FET as a switch

\section{Section B}

States biasing conditions for class A, B, AB and C operation Predicts performance of two-stage class A common-emitter amplifier and two-stage class A common-source amplifier; describes types of interstage coupling: $R C$, direct, transformer

Measures frequence response, signal amplitude, effect of emitter-source bypass capacitor, input and output impedance of twostage amplifier

States functions of components in r.f. amplifier and tuned amplifier Identifies from circuit diagrams single-ended, push-pull and complementary

Observes frequency response, power gain and distortion

States reasons for and effects of parasitic oscillations; suppression

\section{Section C}

Defines noise

Lists sources of noise and precautions to minimise noise; defines and calculates signal-to-noise ratio 


\section{Feedback}

4.1 Feedback Principles

4.2 Feedback in Amplifiers

\section{Simple Resistive-Capacitive Networks}

5.1 Pulse Characteristics

5.2 Integrating and Differentiating Circuits

6. Oscillators

6.1 Principles of Oscillation

6.2 Basic Oscillator Circuits

6.3 Oscillator-biasing

6.4 Oscillator Stability

6.5 Transistor Multivibrators

6.6 Multivibrator-triggering

\section{Integrated Circuits}

7.1 Short History of IC Development

7.2 Linear Integrated Circuits

7.3 Comparison of Integrated and Discrete Circuits

\section{Stabilised Power Supplies}

8.1 Stabilised Power Supply Requirements

8.2 Stabilising Circuit Methods

Answers to Exercises

\section{Section D}

Draws block diagram of basic feedback amplifier

Defines positive and negative feedback; states effects of applying negative feedback to an amplifier in relation to gain; gain stability; distortion; bandwidth; noise; input/output resistances; applies feedback principles to practical circuits

\section{Section E}

Sketches and labels rectangular-pulse wave

Sketches integrating circuit

\section{Section F}

Describes characteristics of basic sinusoidal oscillator circuits

Describes class $\mathrm{A}$ and class $\mathrm{C}$ biasing methods

Describes frequency stability and piezo-electric crystal control Describes action of transistor multivibrators

Explains need for synchronising and triggering multivibrators

Section G

States available range of linear ICs

States advantages of linear operational amplifiers over discrete transistor circuits

\section{Section $\mathrm{H}$}

Identifies requirements for maintaining constant voltage Sketches block diagrams of parallel- and series-stabilised power supplies 


\section{Foreword}

This book is written for one of the many technician courses now being run at technical colleges in accordance with the requirements of the Technician Education Council (TEC). This Council was established in March 1973 as a result of the recommendation of the Government's Haslegrave Committee on Technical Courses and Examinations, which reported in 1969. TEC's functions were to rationalise existing technician courses, including the City and Guilds of London Institute (C.G.L.I.) Technician courses and the Ordinary and Higher National Certificate courses (O.N.C. and H.N.C.), and provide a system of technical education which satisfied the requirements of 'industry' and 'students' but which could be operated economically and efficiently.

Four qualifications are awarded by TEC, namely the Certificate, Higher Certificate, Diploma and Higher Diploma. The Certificate award is comparable with the O.N.C. or with the third year of the C.G.L.I. Technician course, whereas the Higher Certificate is comparable with the H.N.C. or the C.G.L.I. Part III Certificate. The Diploma is comparable with the O.N.D. in Engineering or Technology, the Higher Diploma with the H.N.D. Students study on a part-time or block-release basis for the Certificate and Higher Certificate, whereas the Diploma courses are intended for full-time study. Evening study is possible but not recommended by TEC. The Certificate course consists of fifteen Units and is intended to be studied over a period of three years by students, mainly straight from school, who have three or more C.S.E. Grade III passes or equivalent in appropriate subjects such as mathematics, English and science. The Higher Certificate course consists of a further ten Units, for two years of part-time study, the total time allocation being 900 hours of study for the Certificate and 600 hours for the Higher Certificate. The Diploma requires about 2000 hours of study over two years, the Higher Diploma a further 1500 hours of study for a further two years.

Each student is entered on to a Programme of study on entry to the course; this programme leads to the award of a Technician Certificate, the title of which reflects the area of engineering or science chosen by the student, such as the Telecommunications Certificate or the Mechanical Engineering Certificate. TEC have created three main Sectors of responsibility. 
Sector A responsible for General, Electrical and Mechanical Engineering

Sector B responsible for Building, Mining and Construction Engineering

Sector C responsible for the Sciences, Agriculture, Catering, Graphics and Textiles.

Each Sector is divided into Programme committees, which are responsible for the specialist subjects or programmes, such as A1 for General Engineering, A2 for Electronics and Telecommunications Engineering, A3 for Electrical Engineering, etc. Colleges have considerable control over the content of their intended programmes, since they can choose the Units for their programmes to suit the requirements of local industry, college resources or student needs. These Units can be written entirely by the college, thereafter called a college-devised Unit, or can be supplied as a Standard Unit by one of the Programme committees of TEC. Assessment of every Unit is carried out by the college and a pass in one Unit depends on the attainment gained by the student in his coursework, laboratory work and an end-of-Unit test. TEC moderate college assessment plans and their validation; external assessment by TEC will be introduced at a later stage.

The three-year Certificate course consists of fifteen Units at three Levels: I, II and III, with five Units normally studied per year. A typical programme might be as follows.

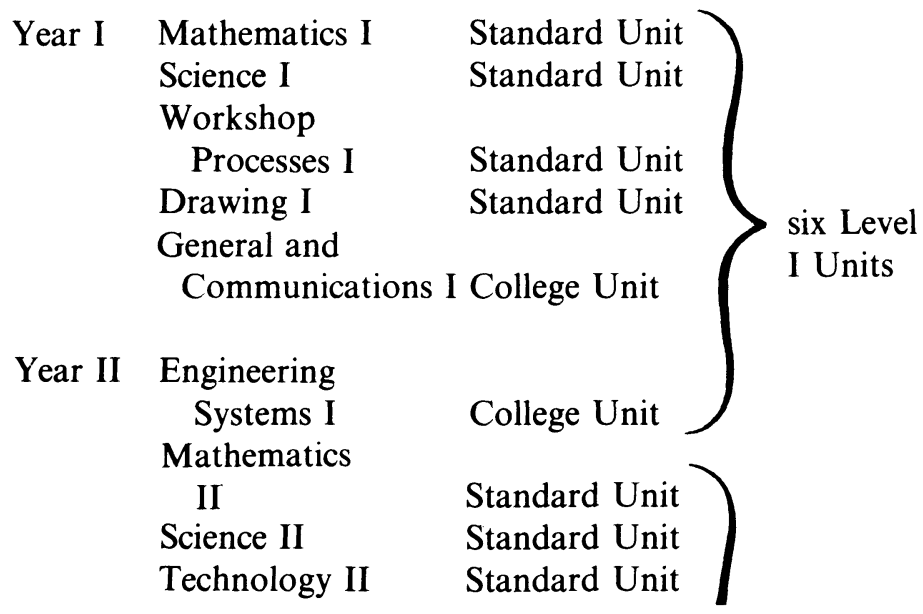

$\begin{array}{cl}\begin{array}{c}\text { General and } \\ \text { Communi- } \\ \text { cations II }\end{array} & \text { College Unit } \\ \begin{array}{c}\text { Industrial } \\ \text { Studies II }\end{array} & \text { College Unit } \\ \text { Engineering } & \text { six Level } \\ \text { Systems II } & \text { College Unit } \\ \text { Mathematics } & \text { Standard Unit } \\ \text { III } & \text { Standard Unit } \\ \text { Science III } & \text { College Unit } \\ \text { Technology III } & \text { III Units }\end{array}$

Entry to each Level I or Level II Unit will carry a prerequisite qualification such as C.S.E. Grade III for Level I or O-level for Level II; certain Craft qualifications will allow students to enter Level II direct, one or two Level I Units being studied as 'trailing' Units in the first year. The study of five Units in one college year results in the allocation of about two hours per week per Unit, and since more subjects are often to be studied than for the comparable City and Guilds course, the treatment of many subjects is more general, with greater emphasis on an understanding of subject topics rather than their application. Every syllabus to every Unit is far more detailed than the comparable O.N.C. or C.G.L.I. syllabus, presentation in Learning Objective form being requested by TEC. For this reason a syllabus, such as that followed by this book, might at first sight seem very long, but analysis of the syllabus will show that 'in-depth' treatment is not necessary - objectives such as 'states Ohm's law' or 'lists the different types of telephone receiver' clearly do not require an understanding of the derivation of the Ohm's law equation or the operation of several telephone receivers.

This book satisfies the learning objectives for one of the many TEC Standard Units, as adopted by many technical colleges for inclusion into their Technician programmes. The treatment of each topic is carried to the depth suggested by TEC, and in a similar way the length of the Unit (sixty hours of study for a full Unit), prerequisite qualifications, credits for alternative qualifications and aims of the Unit have been taken into account by the author. 


\section{Preface}

This book is written for the TEC Standard Unit Electronics III (number U76/009), which is an Essential Unit to be studied at the third and final Certificate year of the Electronics and the Telecommunications Technicians Programmes. This Unit is also included in other programmes as an optional Unit and provides the student with sufficient specialist knowledge to proceed to higher levels of study.

It is assumed that the reader has satisfied all the objectives of the previous Unit, Electronics II (U76/010) or that an equivalent qualification has been obtained. The specification of Electronics III is

Unit title: Electronics III U76/009

Unit Level: III

Unit value: one full Unit

design length: sixty hours

prerequisites: TEC Unit U76/010 or equivalent

aims of the Unit: to develop electronics principles needed as a foundation for further study in electronics and communications engineering at Certificate level.

Electronics III is an important Unit in the Certificate course since a pass in this Unit together with passes in a number of other Units allows the student to proceed to Higher Certificate level where further electronic and communications Units can be studied. It should be remembered that a further Standard Unit, namely Electrical Principles III, is essential for these programmes, the topic areas covered being
a.c. circuits
$R L C$ phasors, reactance and $Q$
three-phase supply factor
d.c. transients
star and delta connections
single-phase transformers
d.c. machines
$C R$ and $L R$ circuits
principles and operation
efficiency, construction and
characteristics
measuring instruments
loading, CRO and uses, errors, bridges.

This Unit follows a TEC syllabus written in objective form, starting with, for example, 'the expected learning outcome is that 
the student compares the properties of a field-effect transistor with valves and bipolar transistors'. For this reason many assessment questions will be of objective form such as multiple-choice-type or short-answer form. A selection of these questions is inserted into this book together with a few longer-type questions which test the various objectives of the unit syllabus. Answers and comments may be found at the end of the book.

All symbols and diagrams conform to the latest British Standards specification although these do vary from time to time. Practical exercises such as structured laboratory work or investigatory work are essential while following this book since many of the concepts that are introduced are of a practical nature and should be testea along with the theoretical knowledge. Project work greatly assists a full understanding of electronic principles, and for this reason several practical circuits are included in the book which take the reader a little further than the syllabus being followed. Readers are advised to experiment with the circuits given and obtain access to the necessary test equipment wherever possible.

Despite the fact that this book closely follows the TEC Standard Unit, it serves as a reference textbook for all students of electronics, together with the previous book Electronics II.

Finally, my thanks go to the TEC staff for their help in the early stages of the writing of this book.

G. D. Bishop 